OPEN ACCESS

Edited by: Noemí de-los-Santos-Álvarez, University of Oviedo, Spain

Reviewed by: Duanping Sun,

Guangdong Pharmaceutical University, China

Dimitra K. Toubanaki,

Pasteur Hellenic Institute, Greece

*Correspondence: Thierry Leichle tleichle@laas.fr Pierre Cordelier pierre.cordelier@inserm.fr

Specialty section: This article was submitted to

Analytical Chemistry,

a section of the journal

Frontiers in Chemistry

Received: 15 July 2019 Accepted: 11 November 2019 Published: 28 November 2019

Citation:

Cacheux J, Bancaud A, Leichlé T and Cordelier P (2019) Technological Challenges and Future Issues for the Detection of Circulating MicroRNAs in Patients With Cancer. Front. Chem. 7:815. doi: 10.3389/fchem.2019.00815

\section{Technological Challenges and Future Issues for the Detection of Circulating MicroRNAs in Patients With Cancer}

\author{
Jean Cacheux ${ }^{1,2}$, Aurélien Bancaud ${ }^{1}$, Thierry Leichlé ${ }^{1 *}$ and Pierre Cordelier ${ }^{2 *}$ \\ ${ }^{1}$ LAAS-CNRS, Université de Toulouse, CNRS, Toulouse, France, ${ }^{2}$ Université Fédérale de Toulouse Midi-Pyrénées, Université \\ Toulouse III Paul Sabatier, CRCT, Toulouse, France
}

In the era of precision medicine, the success of clinical trials, notably for patients diagnosed with cancer, strongly relies on biomarkers with pristine clinical value but also on robust and versatile analytical technologies to ensure proper patients' stratification and treatment. In this review, we will first address whether plasmatic and salivary microRNAs can be considered as a reliable source of biomarkers for cancer diagnosis and prognosis. We will then discuss the pre-analytical steps preceding miRNA quantification (from isolation to purification), and how such process could be biased and time-consuming. Next, we will review the most recent tools derived from micro- and nano-technologies for microRNA detection available to date and how they may compete with current standards. This review will prioritize publications using relevant biological samples. The significance of various physical transduction schemes (mechanical, optical, electrical, etc.) for biological detection will be compared, and pros and cons of each method will be widely discussed. Finally, we will debate on how micro and nanotechnologies could widespread the use of biomarkers in modern medicine, to help manage patients with serious diseases such as cancer.

Keywords: miRNA, sample preparation, micro- and nano-technology, biosensors, cancer

\section{BIOGENESIS AND FUNCTION OF MICRORNAS}

MicroRNAs (miRNAs) are small RNA molecules that inhibit messenger RNA (mRNA) translation by binding to 3'-untranslated region (Bartel, 2004; Kim et al., 2009; Redis et al., 2012). These molecules are tightly involved in the regulation of many physiological processes including development, proliferation, invasion, and apoptosis. The first miRNA molecule, Lin-4, was discovered in 1993 in Caenorhabditis elegans (C. elegans) roundworms (Almeida et al., 2011). It was only seven years later, in 2000, that the second miRNA, Let-7, was identified in the same animal (Pasquinelli et al., 2000). In 2001, such "small RNAs" were coined as miRNAs by Ruvkun and coll (Ruvkun, 2001). Today, the existence of nearly thirty thousand miRNA sequences has been demonstrated in more than 200 eukaryotic species, some of them being conserved between species (miRBase).

MiRNAs are first encoded by RNA polymerase II from DNA as long RNA transcripts (primary RNA molecules, pri-miRNAs) of several thousand nucleotides (Cai et al., 2004). Several pathways give rise to mature miRNA (Miyoshi et al., 2010). One of the best documented pathway starts with the processing of pri-miRNAs into smaller sequences folded in hairpin 
structure ranging from 60 to 110 nucleotides (miRNA precursors, pre-miRNAs) by RNase III Drosha (Lee et al., 2003). These precursors are then exported from the cell nucleus to the cytoplasm through the Exportin-5 (Lund et al., 2004). PremiRNAs are finally cleaved within the cytoplasm by DICER RNase III, to generate double-strand mature miRNA. This causes the RISC (RNA-induced silencing complex) protein complex to selectively bind to the least thermodynamically stable single strand of the miRNA, while the unprotected single-stranded is rapidly degraded [albeit it can be detected to some extent in mouse and human cells (Schwarz et al., 2003)].

miRNA expression is profoundly altered in cancer, and miRNA may participate to carcinogenesis (Calin and Croce, 2006; Hamilton et al., 2013; Lin and Gregory, 2015; Pichler and Calin, 2015). Considering that single miRNAs can regulate 100 of genes, frequently in the context of a cell-specific network, targeting miRNA may prove effective to simultaneously modulate many different oncogenic pathways. Several important reviews have described the many roles and functions of miRNAs during oncogenesis, and have concluded that miRNA expression can serve as a reliable biomarker for patient with cancer (Tsongalis et al., 2013; Aquino-Jarquin, 2017; Rupaimoole and Slack, 2017; Subramaniam et al., 2019; Wang et al., 2019). For the later, miRNAs are involved very early during carcinogenesis and their level of expression reflects the patient's tumor stage (Lu et al., 2005; Balaguer et al., 2010; Hanoun et al., 2010). In addition, we (Buscail et al., 2015; Humeau et al., 2015) and others (Mitchell et al., 2008; Kosaka et al., 2010; Ono et al., 2015) found that miRNAs can be detected in body fluids such as saliva, serum, plasma and urine, paving the way for noninvasive molecular investigations (so called liquid biopsies). While Circulating Tumor Cells (CTCs), cell-free circulating tumor DNA (ctDNA), circulating tumor extracellular vesicles such as exosomes and blood-based protein markers are also promising blood-based circulating biomarkers, as extensively discussed elsewhere (Buscail et al., 2019); in this review, we intend to overview the interest of miRNA as a source of biomarkers for cancer diagnosis and prognosis. We will discuss the pre-analytical steps preceding miRNA quantification, and then review the most recent devices derived from micro- and nano-technologies for microRNA quantification and benchmark their performances with current standards.

\section{FROM SAMPLE PREPARATION TO MIRNA DETECTION: CURRENT STANDARDS TOWARD CLINICAL APPLICATION}

Poorly controlled sample extraction can represent a source of many errors during detection (Figure 1). It is therefore essential to standardize protocols, to compare results and ensure trackability and reproducibility from one lab to the other (Faraldi et al., 2018, 2019). The current lack of consensus is one of the reasons that jeopardizes the widespread use of miRNAs as biomarkers. In addition to patient-related factors, such as age, exercise, diet, region of origin or medication, multiple steps in sample preparation can affect extracted miRNA amounts (Becker and Lockwood, 2013). In this section, we discuss the limitations and challenges associated with processing samples from biological fluids. Considering circulating miRNAs, we focus on the preparation of samples from whole blood products such as plasma and serum, as whole blood complexity exemplifies the main concerns found with other biological sources (Lawrie et al., 2008).

First, let's emphasize on the very high stability of miRNAs when protected by lipid or lipoprotein complexes, among others (El-Hefnawy et al., 2004). Studies showed that room temperature storage for $24 \mathrm{~h}$ has a minimal effect on the stability of endogenous miRNAs in human plasma (Mitchell et al., 2008). Storage at $-80^{\circ} \mathrm{C}$ preserves miRNA content up to 10 months after extraction (Mraz et al., 2009). Similarly, storage for 2-4 years at $-20^{\circ} \mathrm{C}$ very slightly affects miRNAs integrity, which is not the case for longer period of conservation (Grasedieck et al., 2012). Many studies have shown the presence of miRNAs in macrovesicles and exosomes (Gallo et al., 2012; Cheng et al., 2014; Joshi et al., 2015). In this way, exosomes isolation and concentration has been included in miRNA purification workflow to improve miRNA recovery rates. Some research groups even consider exosomes as potential cancer biomarkers (Properzi et al., 2013; Buscail et al., 2019), but it is now more widely accepted that miRNAs resistance to degradation relies to its binding to the Ago2 protein, that prevents from interaction with RNases in solution (Arroyo et al., 2011; Turchinovich et al., 2011).

The first step in pre-analytical operations is sample collection. The sampling tube influences the final quantity of miRNA collected, not only due to rapid degradation of RNAs in untreated tubes, but also because of adsorption to plastic. Kim et al. compared anticoagulant-free tubes, or tubes containing EDTA, heparin, sodium citrate, sodium fluoride or potassium oxalate $(\mathrm{NaF} / \mathrm{KOx})$. They next quantified miR-16 and miR223 miRNAs using reverse quantitative transcription polymerase chain reaction (RT-qPCR) (Kim et al., 2012a). They found that using $\mathrm{NaF} / \mathrm{KOx}$ treated tubes improves the yield of miRNA extraction by 2 -fold when treating plasma, and by three-fold when using serum. Particular attention should be paid to hemolysis, as red blood cell lysis may pollute the final readouts for circulating miRNA analysis (Pritchard et al., 2012). To this end, a panel of miRNA (including miR-16, miR-92a, miR451 , and miR-486) is routinely used to qualify samples purity (Pizzamiglio et al., 2017).

Following sample collection, it is essential to isolate miRNAs from other components present in body fluids. These extraction steps are barely standardized and are principally based on phase separation extraction and/or silica columns that specifically adsorb RNAs. Such purification constraints are essential for proper enzymatic reactions during late-step detection. Phenolchloroform extraction was first implemented in 1987 by Chomczynski and Sacchi (Chomczynski and Sacchi, 1987). This method associates phenol $\left(\mathrm{C}_{6} \mathrm{H}_{5} \mathrm{O}_{5}\right)$ and chloroform $\left(\mathrm{CHCl}_{3}\right)$ with a chaotropic agent, such as guanidinium thiocyanate $\left(\left[\mathrm{CH}_{6} \mathrm{~N}_{3}\right]+\mathrm{SCN}^{-}\right)$, to break down the $3 \mathrm{D}$ structures of proteins (more particularly RNases and RBPs, for RNA binding protein). This method separates proteins, DNA and RNA in a single step, and is compatible with small RNA sequences purification. Total RNA molecules from the aqueous phase 


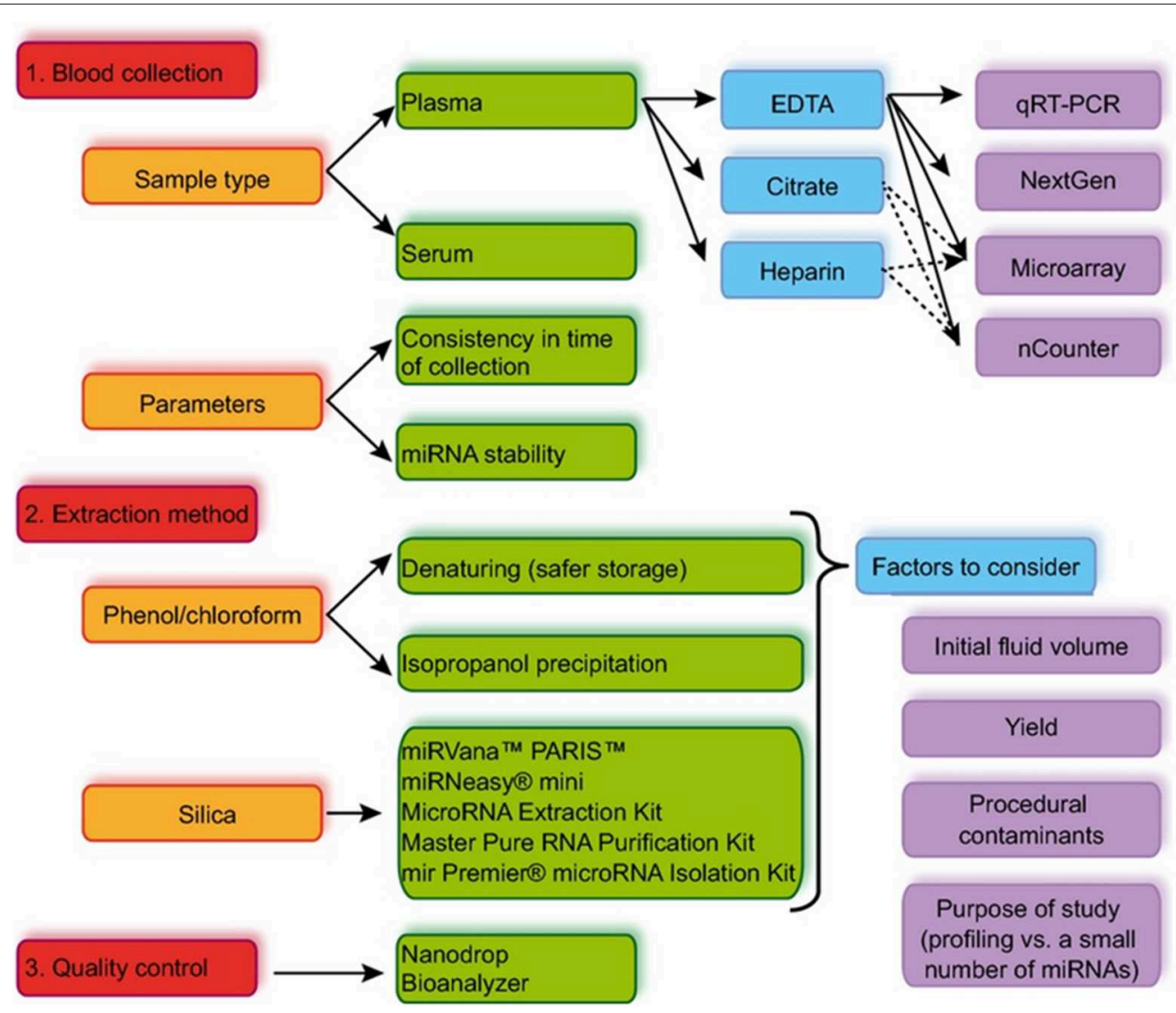

FIGURE 1 | Summary of the standard work flow from sample collection to miRNA detection. Reproduced with permission from Moldovan et al. (2014),

are precipitated using isopropanol (or ethanol). However, recovering low-concentration RNA pellet (typically $<10 \mu \mathrm{g} / \mathrm{mL}$ ) can be problematic, as the pellet can be difficult to visualize and therefore difficult to handle (Rio et al., 2010). Several groups reported that extending precipitation times coupled with centrifugations $\left[20,000-\mathrm{xg}\right.$ for $1 \mathrm{~h}$ at $4^{\circ} \mathrm{C}$ (Hunter et al., 2008)], or glycogen addition improves recovery rates (Duy et al., 2015). Interestingly, phenol-based extraction efficacy varies with the sequence of the miRNA of interest (Kim et al., 2012b) leading to paper retraction (Kim et al., 2011). Silica column filtration to adsorb miRNAs by electrostatic interactions offers a frequent alternative to phenol-based extraction. Following filtration, rinsing steps are required to purify the sample with high efficacy. During this step, alcohol concentration is critical and must be carefully monitored for maximal miRNA recovery. Comparing such commercial kits efficiency is a first step toward standardization (Doleshal et al., 2008; McAlexander et al., 2013).

Quantification and qualification of RNA samples are crucial to address the purity and the integrity of the sample, as this will have direct consequences on detection (Fleige and Pfaffl, 2006), but also to illustrate the size profile and the RNA concentration within the sample of interest. For instance, degradation of the longest RNA fragments can lead to overestimation of miRNA levels (Kirchner et al., 2014). To date, spectrophotometry is the preferred method to quantify RNA with a sensitivity within the $n g / \mu \mathrm{L}$ range. However, this approach hardly distinguishes DNA from RNA in a complex solution. An alternative is to label nucleic acids with fluorescent dyes that show some degree of specificity with single or double-stranded DNA, RNA, or even miRNA (El-Khoury et al., 2016). These fluorescent markers interact electrostatically with nucleic acid chains and emit only when linked to a sequence. This strategy does not only enhance the selectivity but also increases the sensitivity of the approach (100 ng/mL range, Channavajjhala et al., 2014; Ge et al., 2014; Seashols-Williams et al., 2016). However, information on sample purity and size are still lacking. The later concern could be solved using electrophoresis, as this technique has the potential to separate and to quantify nucleic acids by size. This historical approach has recently been brought up to date by considering small size capillary or microfluidic chip, as the reduction of dimensions improves thermal dissipation, and therefore the application of larger electric fields, pushing the detection limits to tenth of $\mathrm{ng} / \mathrm{mL}$. Several technologies, such as Fragment Analyzer (AATI) in capillary electrophoresis or Bioanalyzer (Agilent) and the microLAS ( $\mu$ LAS) platform (Ranchon et al., 2016) in microfluidic chip format, are now routinely used in biological laboratories for sample qualification (Malbec et al., 2018). 
MiRNA quantification methods have evolved from single molecule sequence analysis in days (Northern blot) to relatively short time-to-result quantitative RT-PCR and next-generation sequencing (NGS). However, there are critical challenges associated with small RNA sequencing library preparation, such as biased adapter ligation, formation of adapter dimers, the requirement to size-select the small RNA species, and the necessity to adapt for very low input protocols, especially if circulating biopsies are envisioned (Coenen-Stass et al., 2018). Additionally, direct quantification of specific miRNA sequences in samples requires post-analytical normalization protocols that are not yet standardized. While spiked synthetic miRNA are most often used, Faraldi et al. have recently identified hsamiR-320d as a endogenous calibrator for RT-qPCR analysis (Faraldi et al., 2019). With the most advanced version of RTPCR (RT-digital droplet PCR, ddPCR), amplification of a single sequence is performed in previously isolated "ready-to-use" microscopic drops (from $\mathrm{nL}$ to $\mathrm{pL}$ in volume) using microfluidic systems. Following the Poisson law, each drop contains 4-5 target molecules, strongly limiting the background noise. While more expensive than PCR, ddPCR is solely limited by the number of drops that can be generated. However, the detection of miRNAs using this technique requires implementing controls and optimizing enzymes, primers and probes, as demonstrated by Stein et al. (2017). In a similar way, miRNA quantification can be done using RNA or DNA microarray panels, with the recent emergence of Nanostring technology, a liquid hybridization approach with improved specificity compatible with a variety of sample types including cell lysates, exosomes and biofluids, that is to date routinely used in clinics (Wyman et al., 2011; Kolbert et al., 2013). However, this field of research is still dominated by direct sequencing, and more precisely nextgeneration sequencing (NGS). While the quantity of material collected following liquid biopsy might be limiting, NGS is the unique approach that holds the promise not only to detect genes, mutations or, more generally, specific sequences, but also to discover new sequences, nucleotide by nucleotide, including for miRNA research (Blondal et al., 2017).

To conclude, the cascade of operations leading to the quantification of miRNAs in biofluids can be cumbersome, time-consuming and crippled by serious flaws at all stages of the process, endangering proper quantification of the target analyte (Figure 1). Over the past 10 years, we have witnessed the emergence of new interdisciplinary programs for the titration of miRNAs, at the interface between biology and micro and nanotechnologies, propelled by the phenomenal progress of silicon technology for micro and nanoelectronics, aiming to provide new tools. The ultimate goal of these projects is to translate technological developments into clinical application for patient management.

\section{MICRO AND NANOTECHNOLOGIES FOR THE DETECTION OF MIRNA}

Advances in the field of silicon micro and nanofabrication favored the reduction in size of electronic devices, notably dedicated to computing science, but also within the emerging field of sensors and actuators, with the promise to integrate various functions on a single chip. The first step toward biological applications was to generate devices for measuring chemical species concentration in solution. Biosensors were then referred to as any instrument that provides some sort of measurement in a biological system ( $\mathrm{pH}$, temperature, etc.) (Palchetti and Mascini, 2010). However, this notion evolved very quickly, as Clark defined in the early 1960s a biosensor as the combination of a biological recognition layer with a physical sensor, in that case electrodes coated with enzymes to measure oxygen concentration (Clark et al., 1958; Clark and Lyons, 1962). While measurements were at first mainly carried out by electrochemical sensors, the use of other transduction mechanisms such as optical, mechanical and electrical sensors was quickly implemented. In addition, biorecognition layers with improved specificity, e.g., antibodies, nucleic acids or synthetic ligands, were also developed.

Since the 1980s, microfabrication methods also fostered the emergence of microfluidics (Tabeling and Chen, 2005), defined as the production of fluid channels with dimensions between 1 and $100 \mu \mathrm{m}$ (Whitesides, 2006). This strategy ensures fluid analysis in reduced volumes (nL-fL) with new opportunities for integration and automation. It is therefore perfectly understandable that reducing sensors size, as well as systems to manipulate biological objects, facilitates the investigation of rare molecular events (Tegenfeldt et al., 2004). In addition, the high-level of integration can couple several functions on the same analytical system. Such "laboratory on a chip" holds the promise of downscaling multiple functions of an analytical laboratory, following a "sample-in, answer-out" approach (Easley et al., 2006) that requires a wide variety of expertise in microfabrication, chemistry, biology, microfluidics and bioinformatics (Sahoo et al., 2007).

Coming back to miRNAs analysis, the first step toward micro and nanosensor-based quantification resides in the capture of selected targets by probe molecules and the production of measurable physical signals. Transducing biological recognition into a physical signal by means of micro- and nanofabricated sensors can take different forms (electrical, electrochemical, mechanical or optical) with specific foreseen advantages, such as the high-portability and multiplexing capability coupled to realtime and shorter analysis time. Because of large-scale fabrication capability of the microelectronics industry, these devices can generally be low-cost (although if produced in large quantities). However, limitations are also present: the reproducibility in terms of microfabrication and integration can be difficult to achieve, and, as discussed by Dahlin, reduced size does not always translate into better sensitivity [(Dahlin, 2012), Figure 2 and Table 1].

\section{Electrochemical Detection}

Electrochemical detection involves oxidation/reduction reactions on a set of electrodes. Yin et al. performed electrochemical detection based on the use of gold dendritic nanoparticles functionalized with complementary, molecular beacon type probes targeting candidate miRNAs. These molecular beacons display a stable secondary structure, and they are engrafted 
on a graphene surface (i.e., graphite monolayer corresponding to crystalline hexagonally organized carbon atoms) that serves as a bonding layer. At the basal state, molecular beacons are found in a closed loop shape and do not emit any signal; however, the hairpin opens in the presence of target molecules after incubation during $2 \mathrm{~h} 30$ at room temperature. Next, gold nanoparticles containing complementary strands of LNA (locked nucleic acid) are incubated for $2 \mathrm{~h}$ to interact with the

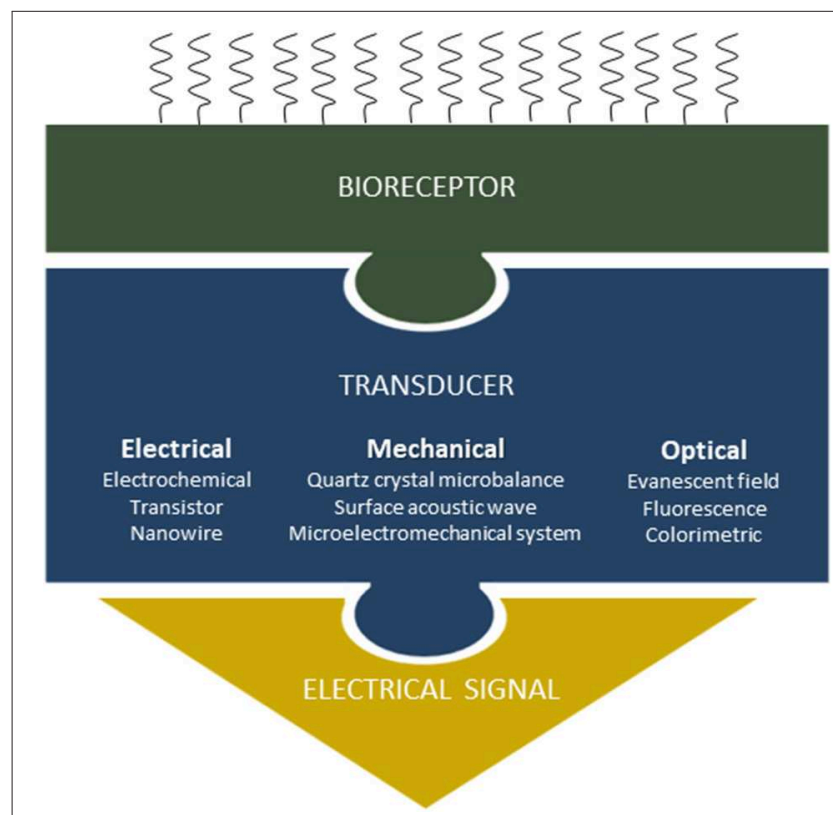

FIGURE 2 | Transduction scheme principles: when the target miRNAs are captured by the probe molecules immobilized onto the sensor surface, a physical change can be measured through different transducing schemes. end of the probe sequence. These nanoparticles also contain biotinylated DNA strands in order to interact with streptavidin molecules coupled to horseradish peroxidases for subsequent electrochemical amplification of the signal. Hydroquinone and hydrogen peroxide are then added to generate a current catalyzed by peroxidases, to indirectly indicate the number of strands hybridized with target miRNAs (Yin et al., 2012). Alternatively, $\mathrm{OsO}_{2}$ (Gao and Yang, 2006), $\mathrm{RuO}_{2}$ (Peng and Gao, 2011) or even silver clusters can be used (Dong et al., 2012). More recently, Travallaie et al. demonstrated miRNA detection directly into unprocessed blood through magnetic gold nanoparticles capture approach and collection onto a surface prior to electrochemical detection with a Limit Of Detection (LOD) down to $10 \mathrm{aM}$ (Tavallaie et al., 2018). These detection methods benefit from relatively good sensitivities, but they require a multitude of steps and specific revelation chemicals that turn into complicated protocols and prevent from real-time detection.

\section{Electrical Detection}

Electrical detection of miRNAs is based on the measurement of a current or a potential difference following, for example, a change in the electrical resistance of a system after hybridization of the miRNA targets with dedicated probe molecules. It generally provides very low LOD at low cost. Nano-pores, which electrical resistance is modulated by the passage of RNAs, can be used in such setting. For instance, in the work of Tian et al., detection is carried out in two stages. First, selected miRNAs are hybridized with miRNA-specific PNA (Peptid Nucleic Acid) probes that are electrically neutral due to the lack of phosphate group in the nucleotide design. Each probe is also conjugated to a polycationic peptide (i.e., a positively charged peptide). The dipole formed upon hybridization with the miRNA target is then directed to the nanopore (formed within a lipid bilayer) via a strong electric field gradient. Unbound miRNAs remain

TABLE 1 | Main characteristics of miRNA detection using tools derived from micro- and nano-technologies.

\begin{tabular}{|c|c|c|c|c|c|}
\hline References & Approach & $\begin{array}{l}\text { Device fabrication } \\
\text { complexity }\end{array}$ & LOD & $\begin{array}{l}\text { Sample complexity } \\
\text { compatibility }\end{array}$ & $\begin{array}{l}\text { Time to result } \\
\text { (Real-time) }\end{array}$ \\
\hline Zhang et al. (2009) & Electrical & High & $1 \mathrm{fM}$ & Medium & $1 \mathrm{~h}(\mathrm{no})$ \\
\hline Tian et al. (2013) & & Medium & $50 \mathrm{pM}$ & Low & $<10 \min$ (yes) \\
\hline Taller et al. (2015) & & High & $13 \mathrm{pM}$ & Low & $1.5 \mathrm{~h}(\mathrm{no})$ \\
\hline Gao and Peng (2011) & Electrochemical & Medium & $6 \mathrm{fM}$ & Low & $4 \mathrm{~h}$ (no) \\
\hline Yin et al. (2012) & & Medium & $60 \mathrm{fM}$ & Medium & $5 \mathrm{~h}(\mathrm{no})$ \\
\hline Dong et al. (2012) & & Medium & $67 \mathrm{fM}$ & Low & $1 \mathrm{~h}(\mathrm{no})$ \\
\hline Tavallaie et al. (2018) & & Medium & $10 \mathrm{aM}$ & High & $2 \mathrm{~h}$ (no) \\
\hline Johnson and Mutharasan (2012) & Mechanical & High & $10 \mathrm{fM}$ & High & $\sim 30$ min (yes) \\
\hline Duffy et al. (2018) & & High & $1 \mathrm{pM}$ & High & $\sim 30$ min (yes) \\
\hline Šípová et al. (2010) & Optical & High & $2 \mathrm{pM}$ & Medium & $<30$ min (yes) \\
\hline Qavi et al. (2011) & & Medium & $10 \mathrm{pM}$ & Low & 40 min (yes) \\
\hline Degliangeli et al. (2014) & & Low & $5 \mathrm{pM}$ & Medium & $2 \mathrm{~h}$ (yes) \\
\hline Joshi et al. (2015) & & High & $32.6 \mathrm{aM}$ & High & $12 \mathrm{~h}$ (no) \\
\hline Liu et al. (2017) & & Medium & $0.6 \mathrm{fM}$ & Medium & $3 \mathrm{~h}(\mathrm{no})$ \\
\hline
\end{tabular}

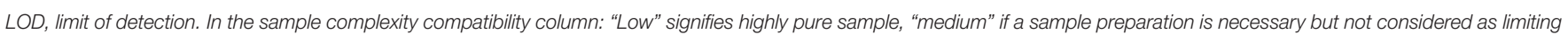
the detection time and "high" means that untreated samples can be detect. As a reference, the typical limit of detection of RT-PCR is 10 aM (unpublished results). 
negatively charged and move away from the nanopores due to the electric field. When miRNA/PNA complexes cross the nanopore, a current shift of a few picoamperes can be measured. This method is highly selective (detection of a single nucleotide difference), with a detection limit in the picomolar range. However, only proof of concept studies are performed to date, using synthetic miRNAs diluted in potassium chloride buffers (Tian et al., 2013). This suggests the presence of strong constraints associated with the use of a buffer solution that must be compatible with an electrical measurement and therefore does not allow for the processing of samples with minimal purification. Along the same line, PNA probes can be grafted onto silicon nanowires, using the amine group of the probe and the silicon surface modified with aldehydes. Because the target miRNA is negatively charged and the PNA probe is electrically neutral, the accumulation of electrical charges modifies the resistance of the nanowire that is translated into miRNA content. This method offers a very good specificity with single base pair discrimination and detection level in the femtomolar range (Zhang et al., 2009). However, manufacturing these devices remains challenging, and incubation and detection must be performed in low ionic strength buffers. A similar strategy can be applied to ion-exchange nanomembranes, where the current voltage characteristic across the membrane is directly correlated to the hybridization rate due to miRNA accumulation. The use of ion-exchange membranes was applied to the detection of miRNAs in cell extracts from pancreatic cancer origin, along with an integrated module for lysing exosomescontaining miRNAs using surface acoustic waves (Figure 3) (Taller et al., 2015).

\section{Mechanical Detection}

Mechanical changes induced by miRNA hybridization on miniaturized suspended structures can be detected and serves for mRNA quantification. This technology, called MEMS for microelectromechanical systems, can be used in static or dynamic modes. In the first case, the capture of target molecules at the surface of the structure results in additional mass and stress, causing a deflection that can be quantified by means of various transduction mechanisms (mainly optical) (Duffy et al., 2018). Alternatively, these systems can be used in dynamic regimes, i.e., in vibration mode, where a decrease in the structure resonance frequency is due to the addition of mass on the surface of the resonator. The dissipation (damping) constant, corresponding to the viscoelastic properties of the material bound to the membrane, may give additional information, notably on the nature of the interactions and the captured molecules organization. Few studies have reported the use of MEMS for miRNA detection. Beams made of silicon zirconate, a piezoelectric material deformed by the application of an electric field, with a surface area of about $1 \mathrm{~mm}^{2}$ covered with a $100 \mathrm{~nm}$ thick layer of gold grafted with thiolated DNA probes complementary to a miRNA target, are one of the most promising MEMS devices for miRNA quantification, as shown by Johnson et al. (Johnson and Mutharasan, 2012). The shift in resonance frequency due to miRNA:probe interaction is directly proportional to the added mass. The measurement is made via periodic electric field $(100 \mathrm{mV})$ application for mechanical excitation of the beam (Figure 3). This technique offers a good selectivity and is labelfree. It is also compatible with detection in complex fluids such as serum. However, reducing the dimensions of MEMS to improve its sensitivity is still a challenge that remains unsolved as well as minimizing the energy loss due to the operation in liquid medium that leads to reduced quality factors, hence performances.

\section{Optical Detection}

Optical methods that have a long tradition in biosensing can also be very helpful for the quantification of miRNAs. Our group recently demonstrated that spatially resolved nanofluidicembedded biosensors supported by fluorescence microscopy authorizes real-time, fast and direct discrimination of singlenucleotide difference (SND) within oligonucleotide sequences in a single step interaction (Cacheux et al., 2018). For this, we designed sensors with much larger linear dimension as compared to the channel depth, with the objective to limit the interaction by the convection rate over the whole sensor. Consequently, targets are fully collected, inducing a non-uniform spatial hybridization profile over the sensor. We managed to discriminate single base pair mismatches on miRNAs sequences by optimizing the interaction temperature and the probe design. This strategy could be applied to any surface-based biosensing transduction scheme, e.g., surface plasmon resonance (SPR) imaging, assuming the integration of nanofluidic channels. Along this line, Šípová et al. used thiolated DNA probes grafted on a gold surface for miRNAs bio-recognition (Šípová et al., 2010). Following hybridization of the probe with the target miRNA, monoclonal antibodies specific of DNA/miRNA interactions are added to amplify the change in refractive index leading to a detection range in the picomolar level after $30 \mathrm{~min}$ of interaction. Magnetic beads functionalized with specific probes coupled to the trombusvirus-encoded suppressor of RNA p19 further improves the sensitivity by capping the miRNA/probe duplex to reach the femtomolar range (Nasheri et al., 2011). Fang et al. designed a very similar detection method, while more complex but with similar sensitivity. In their setting, LNA probes are captured on the surface. Then, they perform poly(A) tail reaction following hybridization of the miRNA with the probe. Gold nanoparticles containing $\operatorname{poly}(\mathrm{T})$ strands hybridize with the newly constituted miRNA poly(A) tail, and detection is performed using SPR, as gold nanoparticles amplify the signal (Fang et al., 2006). Similarly, the work of Liu et al. also supports the use of SPR for the detection of miRNAs. In their work, nanoparticles are modified with aptamers, resulting in very high selectivity. Detection is performed in complex media such as diluted serum, after $50 \mathrm{~min}$ of interaction and several stages of revelation, to reach excellent detection levels ( $\sim 100 \mathrm{fM})$ (Liu et al., 2017). Last but not least, Korc's team recently obtained very impressive results using gold nanoprisms for the detection of miRNA sequences in biological fluid extracts as well as after isolation of circulating exosomes (Joshi et al., 2015) (Figure 3). Detection limits reported are very low, in the order of 100 attomolar with excellent selectivity. However, important errors can be noted when detecting high 
A

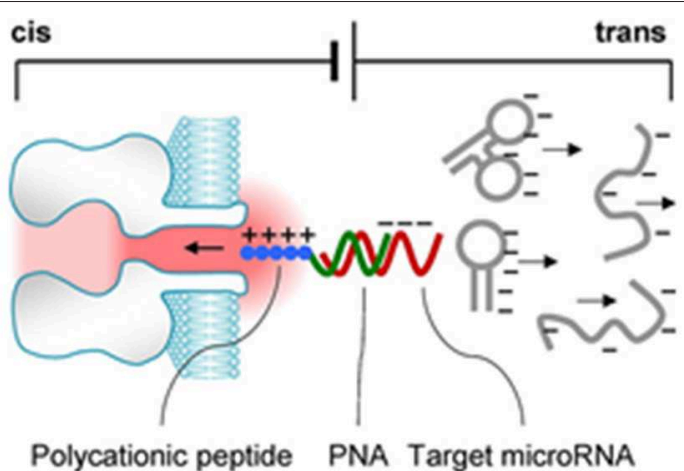

B
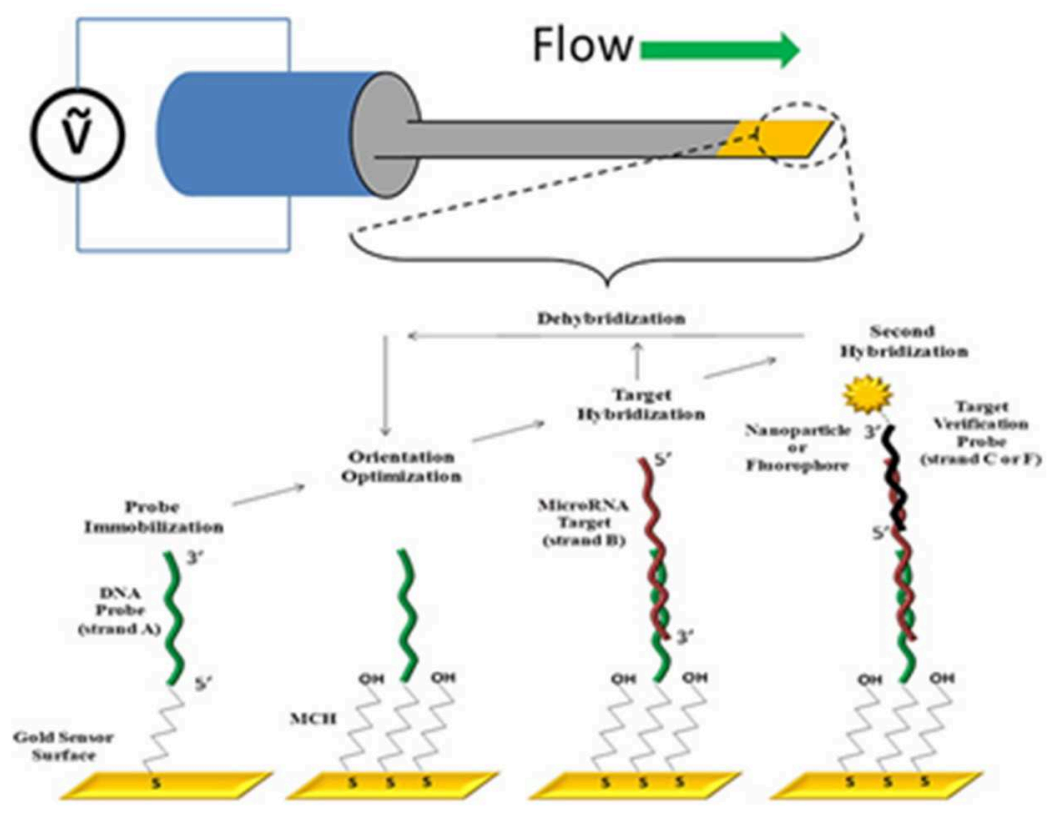

C

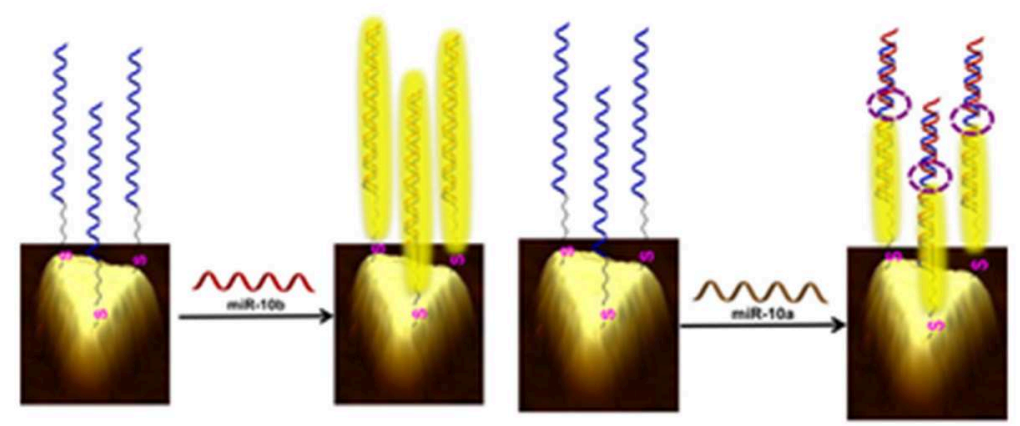

FIGURE 3 | Example of miRNA detection using various micro- and nanofabricated biosensors. (A) Electrical detection of miRNA when passing through a nanoporous membrane. When applying an electric field through the membrane, target miRNAs that are hybridized to specific probes are drawn into the nanopore, while free nucleic acids move away from the pore. Reproduced with permission from Tian et al. (2013). (B) Mechanical detection of miRNA through a biofunctionalised cantilever. By applying a potential difference to the cantilever, its resonant frequency is measured. If a target miRNA interacts with the surface, a shift in the resonance frequency directly proportional to the added mass can be measured. Reproduced with permission from Johnson and Mutharasan (2012). (C) Optical detection of miRNA by surface plasmon resonance using gold nanoprisms. Reproduced with permission from Joshi et al. (2015). 
concentrations of miRNAs $(10 \mathrm{pM}-10 \mathrm{nM})$. In addition, timeto-result is very long $(\sim 12 \mathrm{~h})$ and detection cannot be performed in real time. Another approach, very similar to SPR, calls for silicon micro-rings resonators. DNA probes are linked to silicon via silane functions and hybridized with target miRNAs. Adding S9.6 antibodies specific of the miRNA/DNA interaction amplifies the detection signal, following optical excitation using an external laser. The protocol used in this work is much simpler (Qavi et al., 2011), but the detection threshold is relatively high compared to other optical methods, albeit probe design increases sensitivity (Graybill et al., 2016).

Fluorescence measurements based on fluorophores or quantum dots, which emit light at a specific frequency, have recently emerged as reliable technological approaches to quantify miRNAs. These, detection methods generally involve labeling steps. In their work, Degliangeli et al. immobilized thiolated probes specific to miRNAs on a layer of gold nanoparticles. The surface is then passivated with PEG (Polyethylene Glycol) to limit non-specific interactions. Following DNA probe hybridization with miRNA targets, DNA/miRNA duplexes hydrolysis using endonucleases provokes the release of the fluorophores engrafted on the probes and initially quenched by the gold nanoparticles, and emission of a fluorescent signal that can be measured with a limit of detection of 5 pM (Degliangeli et al., 2014). Due to their excellent optical properties (control of excitation and emission wavelengths, minimal photobleaching, etc.), quantum dots recently became serious alternatives for miRNA detection. $\mathrm{Su}$ et al. generated miRNA-specific DNA probe associated with a quencher on one side, and with a quantum dot on the other side. In the presence of miRNA, the quantum dot fluorescence signal is quenched, due to absorption by the organic quencher (BHQ2) from the DNA probe, and fluorescence measurement can reveal $\mathrm{fM}$ of target sequences (Su et al., 2014). Another alternative is the use of $2 \mathrm{D}$ graphene structures that adsorb and quench the fluorescent of single-stranded sequences specific to target miRNA. When the miRNA target interacts with the surface, duplex is formed, and desorb. Thus, the fluorophore labeled probes move away from the graphene surface, and fluorescence can be measured (Zhu et al., 2015). Other research groups have coupled this approach with more elaborated probe designs such as UNA (unlocked nucleic acid) bases with improved selectivity (Robertson et al., 2017). Along these lines, lateral flow immunoassay analysis (LFIA), also called lateral flow nucleic acid biosensor (LFNAB), can be preferred for microRNA quantification. In LFNAB, DNA-gold nanoparticles based lateral flow nucleic acid biosensor are used for visual detection of microRNA in aqueous solutions and biological samples with low-cost and short analysis time (Gao et al., 2014). Interestingly, the assay can be multiplexed (Zheng et al., 2018). In the later study, such biosensor could successfully detect multiple microRNAs in spiked serum samples without cross-reactivity and matrix-effect. LFNAB detected candidate miRNAs with LOD ranging from 0.061 to $0.085 \mathrm{nM}$, that may open for complementary clinical application, particularly when resources are limited.

\section{WHAT ARE THE NEXT STEPS TO CONVERT MIRNA DETECTION USING MICRO- AND NANO-TECHNOLOGIES INTO CLINICAL APPLICATION?}

As stated before, miRNAs are key players in cancer and can now be considered as a reliable source of biomarkers. They are highly stable and can be detected in body fluids, with the promise to ensure patient stratification. In some specific cases, miRNA detection may be more effective in detecting smaller tumors, micrometastases or early relapse following surgery, notably in pancreatic cancer patients (Buscail et al., 2019). However, miRNAs are not yet routinely used for cancer management. Besides the validation of proper miRNA signatures indicative of cancer by biologists and clinicians, one reason for this could be the lack of robust, reliable, portable, low-cost, specific, and sensitive technologies at the bed side to ensure miRNA quantification in routine practice.

Several technological barriers must be overcome for detecting miRNAs directly in complex fluids (plasma, saliva, urine, etc.). First, circulating miRNAs are most of the time trapped with proteins or within exosomes in biofluids. It is thus necessary to devise specific technological bricks to release these low molecular weight RNA molecules before proceeding to analysis and detection. Interestingly, Taller et al. created a device with the ability to lyse exosomes-containing miRNA directly on a chip (Taller et al., 2015). Unfortunately, the electrical detection system is not compatible with complex fluids, strengthening the fact that the whole picture (pre-analytic and analytic steps, specific targets or target environments) must be considered to generate the best technological offer.

The next key step is to better address sample preparation. For biologists, standard amplification-based detection methods require high levels of purity due to the critical sensitivity of enzymatic reactions. Generally, extraction protocols favor quality rather than quantity, which may represent a major issue when dealing with devices that require relatively high amounts of starting material. One way to achieve this goal would be to invent a novel microfluidic technology for the concentration and separation of oligonucleotide sequences. This is already true for DNA fragments, using the lab-on-chip system $\mu$ LAS developed by Bancaud et al. that concentrates, separates, and detects nucleic acids in a single module (Malbec et al., 2019). Target concentration is achieved by applying an electric field opposite to the solution flow of viscoelastic liquids. It would be interesting to develop this technology for the concentration of miRNA sequences.

Several groups are actively working to increase the sensitivity of micro- and nano-technology derived platforms to improve miRNA detection in liquid biopsies. Their goal is to provide novel devices that detect and quantify several candidate biomarkers, ideally from different molecular classes, as composite signatures, such as Cancer-SEEK, that recently revealed their clinical value for cancer early detection and follow-up (Cohen et al., 2018). The coupling of several targets on the same detection platform remains a scientific challenge with strong clinical 
potential. One interesting option for multiple functionalization (with resolutions in the order of $10 \mu \mathrm{m}$ ) could be the use of microcontact printing or tools for drop delivery, derived from MEMS technology and capable in theory of sampling and depositing very small volumes of solution (Berthet-Duroure et al., 2008; Salomon et al., 2012). Such experiment would be a first step toward multiplexing detection systems.

This synergy of expertise may ultimately pave the way for implantable biosensors that can evaluate disease indicators, such as miRNAs, in real-time in human bodies. While biocompatibility and long-term stability are still being addressed, prototypes have recently emerged for the management of patients with various diseases. As an example, wireless sensor implant targeting real-time blood glucose body levels were recently developed by a molecular nanotechnology company expert in MEMS called Zyvex ${ }^{1}$. This novel portable device does not only indicate glucose levels but also communicates with the clinical management system. Extra-body circulation systems may represent a first step to address miRNA quantification in blood of patients with cancer, for the first time in

${ }^{1}$ https://www.zyvexlabs.com/

\section{REFERENCES}

Almeida, M. I., Reis, R. M., and Calin, G. A. (2011). MicroRNA history: discovery, recent applications, and next frontiers. Mutat. Res. Mol. Mech. Mutagen. 717, 1-8. doi: 10.1016/j.mrfmmm.2011.03.009

Aquino-Jarquin, G. (2017). Emerging role of CRISPR/Cas9 technology for MicroRNAs editing in cancer research. Cancer Res. 77, 6812-6817. doi: 10.1158/0008-5472.CAN-17-2142

Arroyo, J. D., Chevillet, J. R., Kroh, E. M., Ruf, I. K., Pritchard, C. C., Gibson, D. F., et al. (2011). Argonaute 2 complexes carry a population of circulating microRNAs independent of vesicles in human plasma. Proc. Natl. Acad. Sci. U.S.A. 108, 5003-5008. doi: 10.1073/pnas.1019055108

Balaguer, F., Link, A., Lozano, J. J., Cuatrecasas, M., Nagasaka, T., Boland, C. R., et al. (2010). Epigenetic silencing of miR-137 is an early event in colorectal carcinogenesis. Cancer Res. 70, 6609-6618. doi: 10.1158/0008-5472.CAN-10-0622

Bartel, D. P. (2004). MicroRNAs: genomics, biogenesis, mechanism, and function. Cell 116, 281-297. doi: 10.1016/S0092-8674(04)00045-5

Becker, N., and Lockwood, C. M. (2013). Pre-analytical variables in miRNA analysis. Clin. Biochem. 46, 861-868. doi: 10.1016/j.clinbiochem.2013.02.015

Berthet-Duroure, N., Leïchlé, T., Pourciel, J.-B., Martin, C., Bausells, J., LoraTamayo, E., et al. (2008). Interaction of biomolecules sequentially deposited at the same location using a microcantilever-based spotter. Biomed. Microdevices 10, 479-487. doi: 10.1007/s10544-007-9156-1

Blondal, T., Brunetto, M. R., Cavallone, D., Mikkelsen, M., Thorsen, M., Mang, Y., et al. (2017). Genome-wide comparison of next-generation sequencing and qPCR platforms for microRNA profiling in serum. Methods Mol. Biol. 1580, 21-44. doi: 10.1007/978-1-4939-6866-4_3

Buscail, E., Maulat, C., Muscari, F., Chiche, L., Cordelier, P., Dabernat, S., et al. (2019). Liquid biopsy approach for pancreatic ductal adenocarcinoma. Cancers 11:852. doi: 10.3390/cancers11060852

Buscail, L., Bournet, B., Vernejoul, F., Cambois, G., Lulka, H., Hanoun, N., et al. (2015). First-in-man phase I clinical trial of gene therapy for advanced pancreatic cancer: safety, biodistribution and preliminary clinical findings. Mol. Ther. J. Am. Soc. Gene Ther. 23, 779-789. doi: 10.1038/mt.2015.1

Cacheux, J., Brut, M., Bancaud, A., Cordelier, P., and Leïchlé, T. (2018). Spatial analysis of nanofluidic-embedded biosensors for wash-free single-nucleotide difference discrimination. ACS Sens. 3, 606-611. doi: 10.1021/acssensors.7b00667 real-time and longitudinal studies. Thus, by and large, micro and nanotechnologies offer significant promise in the medical device community. They may also pose several regulatory challenges, which as time goes by, will probably become more pressing than the technical challenges. Nevertheless, new technologies have the potential to revolutionize cancer management when associated with the right candidate biomarkers for the right patient or disease state, to help manage patients with serious diseases such as cancer, following a precision medicine strategy.

\section{AUTHOR CONTRIBUTIONS}

PC wrote a draft and finalized the manuscript. JC built Table 1 and inserted figures and the biobliographic references. JC, TL, and $\mathrm{AB}$ significantly edited the manuscript.

\section{FUNDING}

This program was partly financed by a grant from Toulouse IDEX (Oncodevice program). JC received a fellowship from Fondation ARC.

Cai, X., Hagedorn, C. H., and Cullen, B. R. (2004). Human microRNAs are processed from capped, polyadenylated transcripts that can also function as mRNAs. RNA N. Y. N 10, 1957-1966. doi: 10.1261/rna.7135204

Calin, G. A., and Croce, C. M. (2006). MicroRNA signatures in human cancers. Nat. Rev. Cancer 6, 857-866. doi: 10.1038/nrc1997

Channavajjhala, S. K., Rossato, M., Morandini, F., Castagna, A., Pizzolo, F., Bazzoni, F., et al. (2014). Optimizing the purification and analysis of miRNAs from urinary exosomes. Clin. Chem. Lab. Med. 52, 345-354. doi: 10.1515/cclm-2013-0562

Cheng, L., Sharples, R. A., Scicluna, B. J., and Hill, A. F. (2014). Exosomes provide a protective and enriched source of miRNA for biomarker profiling compared to intracellular and cell-free blood. J. Extracell. Vesicles 3:23743. doi: 10.3402/jev.v3.23743

Chomczynski, P., and Sacchi, N. (1987). Single-step method of RNA isolation by acid guanidinium thiocyanate-phenol-chloroform extraction. Anal. Biochem. 162, 156-159. doi: 10.1016/0003-2697(87)90021-2

Clark, L. C., Kaplan, S., Matthews, E. C., Edwards, F. K., and Helmsworth, J. A. (1958). Monitor and control of blood oxygen tension and $\mathrm{pH}$ during total body perfusion. J. Thorac. Surg. 36, 488-496.

Clark, L. C., and Lyons, C. (1962). Electrode systems for continuous monitoring in cardiovascular surgery. Ann. N. Y. Acad. Sci. 102, 29-45. doi: 10.1111/j.1749-6632.1962.tb13623.x

Coenen-Stass, A. M. L., Magen, I., Brooks, T., Ben-Dov, I. Z., Greensmith, L., Hornstein, E., et al. (2018). Evaluation of methodologies for microRNA biomarker detection by next generation sequencing. RNA Biol. 15, 1133-1145. doi: 10.1080/15476286.2018.1514236

Cohen, J. D., Li, L., Wang, Y., Thoburn, C., Afsari, B., Danilova, L., et al. (2018). Detection and localization of surgically resectable cancers with a multi-analyte blood test. Science 359, 926-930. doi: 10.1126/science.aar3247

Dahlin, A. B. (2012). Size matters: problems and advantages associated with highly miniaturized sensors. Sensors 12, 3018-3036. doi: 10.3390/s120303018

Degliangeli, F., Kshirsagar, P., Brunetti, V., Pompa, P. P., and Fiammengo, R. (2014). Absolute and Direct MicroRNA quantification using DNA-Gold nanoparticle probes. J. Am. Chem. Soc. 136, 2264-2267. doi: 10.1021/ja412152x

Doleshal, M., Magotra, A. A., Choudhury, B., Cannon, B. D., Labourier, E., and Szafranska, A. E. (2008). Evaluation and validation of total RNA extraction methods for microRNA expression analyses in formalin-fixed, paraffinembedded tissues. J. Mol. Diagn. 10, 203-211. doi: 10.2353/jmoldx.2008. 070153 
Dong, H., Jin, S., Ju, H., Hao, K., Xu, L.-P., Lu, H., et al. (2012). Trace and label-free MicroRNA detection using oligonucleotide encapsulated silver nanoclusters as probes. Anal. Chem. 84, 8670-8674. doi: 10.1021/ac301860v

Duffy, J., Padovani, F., Brunetti, G., Noy, P., Certa, U., and Hegner, M. (2018). Towards personalised rapid label free miRNA detection for cancer and liver injury diagnostics in cell lysates and blood based samples. Nanoscale 10, 12797-12804. doi: 10.1039/C8NR03604G

Duy, J., Koehler, J. W., Honko, A. N., and Minogue, T. D. (2015). Optimized microRNA purification from TRIzol-treated plasma. BMC Genomics 16:95. doi: 10.1186/s12864-015-1299-5

Easley, C. J., Karlinsey, J. M., Bienvenue, J. M., Legendre, L. A., Roper, M. G., Feldman, S. H., et al. (2006). A fully integrated microfluidic genetic analysis system with sample-in-answer-out capability. Proc. Natl. Acad. Sci. U.S.A. 103, 19272-19277. doi: 10.1073/pnas.0604663103

El-Hefnawy, T., Raja, S., Kelly, L., Bigbee, W. L., Kirkwood, J. M., Luketich, J. D., et al. (2004). Characterization of amplifiable, circulating RNA in plasma and its potential as a tool for cancer diagnostics. Clin. Chem. 50, 564-573. doi: 10.1373/clinchem.2003.028506

El-Khoury, V., Pierson, S., Kaoma, T., Bernardin, F., and Berchem, G. (2016). Assessing cellular and circulating miRNA recovery: the impact of the RNA isolation method and the quantity of input material. Sci. Rep. 6:19529. doi: $10.1038 /$ srep 19529

Fang, S., Lee, H. J., Wark, A. W., and Corn, R. M. (2006). Attomole microarray detection of MicroRNAs by nanoparticle-amplified SPR imaging measurements of surface polyadenylation reactions. J. Am. Chem. Soc. 128, 14044-14046. doi: 10.1021/ja065223p

Faraldi, M., Gomarasca, M., Banfi, G., and Lombardi, G. (2018). Free circulating miRNAs measurement in clinical settings: the still unsolved issue of the normalization. Adv. Clin. Chem. 87, 113-139. doi: 10.1016/bs.acc.2018.07.003

Faraldi, M., Gomarasca, M., Sansoni, V., Perego, S., Banfi, G., and Lombardi, G. (2019). Normalization strategies differently affect circulating miRNA profile associated with the training status. Sci. Rep. 9, 1584. doi: 10.1038/s41598-019-38505-x

Fleige, S., and Pfaffl, M. W. (2006). RNA integrity and the effect on the real-time qRT-PCR performance. Mol. Aspects Med. 27, 126-139. doi: $10.1016 /$ j.mam.2005.12.003

Gallo, A., Tandon, M., Alevizos, I., and Illei, G. G. (2012). The majority of MicroRNAs detectable in serum and saliva is concentrated in exosomes. PLoS ONE 7:e30679. doi: 10.1371/journal.pone.0030679

Gao, Z., and Peng, Y. (2011). A highly sensitive and specific biosensor for ligationand PCR-free detection of microRNAs. Biosens Bioelectron. 26, 3768-3773. doi: 10.1016/j.bios.2011.02.029

Gao, X., Xu, H., Baloda, M., Gurung, A. S., Xu, L.-P., Wang, T., et al. (2014). Visual detection of microRNA with lateral flow nucleic acid biosensor. Biosens. Bioelectron. 54, 578-584. doi: 10.1016/j.bios.2013.10.055

Gao, Z., and Yang, Z. (2006). Detection of MicroRNAs using electrocatalytic nanoparticle tags. Anal. Chem. 78, 1470-1477. doi: 10.1021/ac051726m

Ge, Q., Zhou, Y., Lu, J., Bai, Y., Xie, X., and Lu, Z. (2014). miRNA in plasma exosome is stable under different storage conditions. Mol. Basel Switz. 19, 1568-1575. doi: 10.3390/molecules19021568

Grasedieck, S., Schöler, N., Bommer, M., Niess, J. H., Tumani, H., Rouhi, A., et al. (2012). Impact of serum storage conditions on microRNA stability. Leukemia 26, 2414-2416. doi: 10.1038/leu.2012.106

Graybill, R. M., Para, C. S., and Bailey, R. C. (2016). PCR-Free, multiplexed expression profiling of microRNAs using silicon photonic microring resonators. Anal. Chem. 88, 10347-10351. doi: 10.1021/acs.analchem.6b03350

Hamilton, M. P., Rajapakshe, K., Hartig, S. M., Reva, B., McLellan, M. D., Kandoth, C., et al. (2013). Identification of a pan-cancer oncogenic microRNA superfamily anchored by a central core seed motif. Nat. Commun. 4:2730. doi: $10.1038 /$ ncomms 3730

Hanoun, N., Delpu, Y., Suriawinata, A. A., Bournet, B., Bureau, C., Selves, J., et al. (2010). The silencing of microRNA 148a production by DNA hypermethylation is an early event in pancreatic carcinogenesis. Clin. Chem. 56, 1107-1118. doi: 10.1373/clinchem.2010.144709

Humeau, M., Vignolle-Vidoni, A., Sicard, F., Martins, F., Bournet, B., Buscail, L., et al. (2015). Salivary MicroRNA in pancreatic cancer patients. PLoS ONE 10:e0130996. doi: 10.1371/journal.pone.0130996

Hunter, M. P., Ismail, N., Zhang, X., Aguda, B. D., Lee, E. J., Yu, L., et al. (2008). Detection of microRNA expression in human peripheral blood microvesicles. PLoS ONE 3:e3694. doi: 10.1371/journal.pone.0003694
Johnson, B. N., and Mutharasan, R. (2012). Sample preparation-free, realtime detection of microRNA in human serum using piezoelectric cantilever biosensors at attomole level. Anal. Chem. 84, 10426-10436. doi: $10.1021 / \mathrm{ac} 303055 \mathrm{c}$

Joshi, G. K., Deitz-McElyea, S., Liyanage, T., Lawrence, K., Mali, S., Sardar, R., et al. (2015). Label-free nanoplasmonic-based short noncoding RNA sensing at attomolar concentrations allows for quantitative and highly specific assay of MicroRNA-10b in biological fluids and circulating exosomes. ACS Nano 9 , 11075-11089. doi: 10.1021/acsnano.5b04527

Kim, D.-J., Linnstaedt, S., Palma, J., Park, J. C., Ntrivalas, E., KwakKim, J. Y. H., et al. (2012a). Plasma components affect accuracy of circulating cancer-related microRNA quantitation. J. Mol. Diagn. 14, 71-80. doi: 10.1016/j.jmoldx.2011.09.002

Kim, V. N., Han, J., and Siomi, M. C. (2009). Biogenesis of small RNAs in animals. Nat. Rev. Mol. Cell Biol. 10, 126-139. doi: 10.1038/nrm2632

Kim, Y.-K., Yeo, J., Ha, M., Kim, B., and Kim, V. N. (2011). Retracted: cell adhesion-dependent control of MicroRNA decay. Mol. Cell 43, 1005-1014. doi: 10.1016/j.molcel.2011.07.031

Kim, Y.-K., Yeo, J., Kim, B., Ha, M., and Kim, V. N. (2012b). Short structured RNAs with low GC content are selectively lost during extraction from a small number of cells. Mol. Cell 46, 893-895. doi: 10.1016/j.molcel.2012.05.036

Kirchner, B., Paul, V., Riedmaier, I., and Pfaffl, M. W. (2014). mRNA and microRNA purity and integrity: the key to success in expression profiling. Methods Mol. Biol. 1160, 43-53. doi: 10.1007/978-1-4939-0733-5_5

Kolbert, C. P., Feddersen, R. M., Rakhshan, F., Grill, D. E., Simon, G., Middha, S., et al. (2013). Multi-platform analysis of microRNA expression measurements in RNA from fresh frozen and FFPE tissues. PLoS ONE 8:e52517. doi: 10.1371/journal.pone.0052517

Kosaka, N., Iguchi, H., and Ochiya, T. (2010). Circulating microRNA in body fluid: a new potential biomarker for cancer diagnosis and prognosis. Cancer Sci. 101, 2087-2092. doi: 10.1111/j.1349-7006.2010.01650.x

Lawrie, C. H., Gal, S., Dunlop, H. M., Pushkaran, B., Liggins, A. P., Pulford, K., et al. (2008). Detection of elevated levels of tumour-associated microRNAs in serum of patients with diffuse large B-cell lymphoma. Br. J. Haematol. 141, 672-675. doi: 10.1111/j.1365-2141.2008.07077.x

Lee, Y., Ahn, C., Han, J., Choi, H., Kim, J., Yim, J., et al. (2003). The nuclear RNase III Drosha initiates microRNA processing. Nature 425, 415-419. doi: 10.1038/nature 01957

Lin, S., and Gregory, R. I. (2015). MicroRNA biogenesis pathways in cancer. Nat. Rev. Cancer 15, 321-333. doi: 10.1038/nrc3932

Liu, R., Wang, Q., Li, Q., Yang, X., Wang, K., and Nie, W. (2017). Surface plasmon resonance biosensor for sensitive detection of microRNA and cancer cell using multiple signal amplification strategy. Biosens. Bioelectron. 87, 433-438. doi: 10.1016/j.bios.2016.08.090

Lu, J., Getz, G., Miska, E. A., Alvarez-Saavedra, E., Lamb, J., Peck, D., et al. (2005). MicroRNA expression profiles classify human cancers. Nature 435, 834-838. doi: 10.1038 /nature03702

Lund, E., Güttinger, S., Calado, A., Dahlberg, J. E., and Kutay, U. (2004). Nuclear export of microRNA precursors. Science 303, 95-98. doi: 10.1126/science.1090599

Malbec, R., Cacheux, J., Cordelier, P., Leichlé, T., Joseph, P., and Bancaud, A. (2018). Microfluidics for minute DNA sample analysis: open challenges for genetic testing of cell-free circulating DNA in blood plasma. Micro Nano Eng. 1, 25-32. doi: 10.1016/j.mne.2018.10.003

Malbec, R., Chami, B., Aeschbach, L., Ruiz Buendía, G. A., Socol, M., Joseph, P., et al. (2019). MLAS: sizing of expanded trinucleotide repeats with femtomolar sensitivity in less than 5 minutes. Sci. Rep. 9:23. doi: 10.1038/s41598-018-36632-5

McAlexander, M. A., Phillips, M. J., and Witwer, K. W. (2013). Comparison of methods for miRNA extraction from plasma and quantitative recovery of RNA from cerebrospinal fluid. Front. Genet. 4:83. doi: 10.3389/fgene.2013.00083

Mitchell, P. S., Parkin, R. K., Kroh, E. M., Fritz, B. R., Wyman, S. K., PogosovaAgadjanyan, E. L., et al. (2008). Circulating microRNAs as stable blood-based markers for cancer detection. Proc. Natl. Acad. Sci. U.S.A. 105, 10513-10518. doi: 10.1073/pnas.0804549105

Miyoshi, K., Miyoshi, T., and Siomi, H. (2010). Many ways to generate microRNAlike small RNAs: non-canonical pathways for microRNA production. $\mathrm{Mol}$. Genet. Genomics 284, 95-103. doi: 10.1007/s00438-010-0556-1

Moldovan, L., Batte, K. E., Trgovcich, J., Wisler, J., Marsh, C. B., and Piper, M. (2014). Methodological challenges in utilizing miRNAs as circulating biomarkers. J. Cell. Mol. Med. 18, 371-390. doi: 10.1111/jcmm.12236 
Mraz, M., Malinova, K., Mayer, J., and Pospisilova, S. (2009). MicroRNA isolation and stability in stored RNA samples. Biochem. Biophys. Res. Commun. 390, 1-4. doi: 10.1016/j.bbrc.2009.09.061

Nasheri, N., Cheng, J., Singaravelu, R., Wu, P., McDermott, M. T., and Pezacki, J. P. (2011). An enzyme-linked assay for the rapid quantification of microRNAs based on the viral suppressor of RNA silencing protein p19. Anal. Biochem. 412, 165-172. doi: 10.1016/j.ab.2011.01.030

Ono, S., Lam, S., Nagahara, M., and Hoon, D. S. B. (2015). Circulating microRNA biomarkers as liquid biopsy for cancer patients: pros and cons of current assays. J. Clin. Med. 4, 1890-1907. doi: 10.3390/jcm4101890

Palchetti, I., and Mascini, M. (2010). "Biosensor technology: a brief history," in Sensors and Microsystems Lecture Notes in Electrical Engineering, eds P. Malcovati, A. Baschirotto, A. d'Amico, and C. Natale (Springer), 15-23. doi: 10.1007/978-90-481-3606-3_2

Pasquinelli, A. E., Reinhart, B. J., Slack, F., Martindale, M. Q., Kuroda, M. I., Maller, B., et al. (2000). Conservation of the sequence and temporal expression of let-7 heterochronic regulatory RNA. Nature 408:86. doi: 10.1038/35040556

Peng, Y., and Gao, Z. (2011). Amplified detection of MicroRNA based on ruthenium oxide nanoparticle-initiated deposition of an insulating film. Anal. Chem. 83, 820-827. doi: 10.1021/ac102370s

Pichler, M., and Calin, G. A. (2015). MicroRNAs in cancer: from developmental genes in worms to their clinical application in patients. Br. J. Cancer 113, 569-573. doi: 10.1038/bjc.2015.253

Pizzamiglio, S., Zanutto, S., Ciniselli, C. M., Belfiore, A., Bottelli, S., Gariboldi, M., et al. (2017). A methodological procedure for evaluating the impact of hemolysis on circulating microRNAs. Oncol. Lett. 13, 315-320. doi: 10.3892/ol.2016.5452

Pritchard, C. C., Kroh, E., Wood, B., Arroyo, J. D., Dougherty, K. J., Miyaji, M. M., et al. (2012). Blood cell origin of circulating microRNAs: a cautionary note for cancer biomarker studies. Cancer Prev. Res. 5, 492-497. doi: 10.1158/1940-6207.CAPR-11-0370

Properzi, F., Logozzi, M., and Fais, S. (2013). Exosomes: the future of biomarkers in medicine. Biomark. Med. 7, 769-778. doi: 10.2217/bmm.13.63

Qavi, A. J., Kindt, J. T., Gleeson, M. A., and Bailey, R. C. (2011). AntiDNA:RNA antibodies and silicon photonic microring resonators: increased sensitivity for multiplexed microRNA detection. Anal. Chem. 83, 5949-5956. doi: $10.1021 /$ ac201340s

Ranchon, H., Malbec, R., Picot, V., Boutonnet, A., Terrapanich, P., Joseph, P., et al. (2016). DNA separation and enrichment using electro-hydrodynamic bidirectional flows in viscoelastic liquids. Lab. Chip 16, 1243-1253. doi: 10.1039/C5LC01465D

Redis, R. S., Berindan-Neagoe, I., Pop, V. I., and Calin, G. A. (2012). Non-coding RNAs as theranostics in human cancers. J. Cell. Biochem. 113, 1451-1459. doi: $10.1002 /$ jcb. 24038

Rio, D. C., Ares, M., Hannon, G. J., and Nilsen, T. W. (2010). Purification of RNA using TRIzol (TRI reagent). Cold Spring Harb. Protoc. 2010:pdb.prot5439. doi: $10.1101 /$ pdb.prot5439

Robertson, N. M., Toscano, A. E., LaMantia, V. E., Hizir, M. S., Rana, M., Balcioglu, M., et al. (2017). Unlocked nucleic acids for miRNA detection using two dimensional nano-graphene oxide. Biosens. Bioelectron. 89, 551-557. doi: 10.1016/j.bios.2016.02.058

Rupaimoole, R., and Slack, F. J. (2017). MicroRNA therapeutics: towards a new era for the management of cancer and other diseases. Nat. Rev. Drug Discov. 16, 203-222. doi: 10.1038/nrd.2016.246

Ruvkun, G. (2001). Glimpses of a tiny RNA World. Science 294, 797-799. doi: 10.1126/science.1066315

Sahoo, S. K., Parveen, S., and Panda, J. J. (2007). The present and future of nanotechnology in human health care. Nanomed. Nanotechnol. Biol. Med. 3, 20-31. doi: 10.1016/j.nano.2006.11.008

Salomon, S., Leïchlé, T., Dezest, D., Seichepine, F., Guillon, S., Thibault, C., et al. (2012). Arrays of nanoelectromechanical biosensors functionalized by microcontact printing. Nanotechnology 23:495501. doi: 10.1088/0957-4484/23/49/495501

Schwarz, D. S., Hutvágner, G., Du, T., Xu, Z., Aronin, N., and Zamore, P. D. (2003). Asymmetry in the assembly of the RNAi enzyme complex. Cell 115, 199-208. doi: 10.1016/S0092-8674(03)00759-1

Seashols-Williams, S., Lewis, C., Calloway, C., Peace, N., Harrison, A., HayesNash, C., et al. (2016). High-throughput miRNA sequencing and identification of biomarkers for forensically relevant biological fluids. Electrophoresis 37, 2780-2788. doi: 10.1002/elps.201600258
Šípová, H., Zhang, S., Dudley, A. M., Galas, D., Wang, K., and Homola, J. (2010). Surface plasmon resonance biosensor for rapid label-free detection of microribonucleic acid at subfemtomole level. Anal. Chem. 82, 10110-10115. doi: 10.1021/ac102131s

Stein, E. V., Duewer, D. L., Farkas, N., Romsos, E. L., Wang, L., and Cole, K. D. (2017). Steps to achieve quantitative measurements of microRNA using two step droplet digital PCR. PLoS ONE 12:e0188085. doi: 10.1371/journal.pone.0188085

Su, S., Fan, J., Xue, B., Yuwen, L., Liu, X., Pan, D., et al. (2014). DNA-conjugated quantum dot nanoprobe for high-sensitivity fluorescent detection of DNA and micro-RNA. ACS Appl. Mater. Interfaces 6, 1152-1157. doi: 10.1021/am404811j

Subramaniam, S., Jeet, V., Clements, J. A., Gunter, J. H., and Batra, J. (2019). Emergence of MicroRNAs as key players in cancer cell metabolism. Clin. Chem. 65, 1090-1101. doi: 10.1373/clinchem.2018.299651

Tabeling, P., and Chen, S. (2005). Introduction to Microfluidics. Oxford, NY: Oxford University Press.

Taller, D., Richards, K., Slouka, Z., Senapati, S., Hill, R. B., et al. (2015). Onchip surface acoustic wave lysis and ion-exchange nanomembrane detection of exosomal RNA for pancreatic cancer study and diagnosis. Lab. Chip 15, 1656-1666. doi: 10.1039/C5LC00036J

Tavallaie, R., McCarroll, J., Grand, M. L., Ariotti, N., Schuhmann, W., Bakker, E., et al. (2018). Nucleic acid hybridization on an electrically reconfigurable network of gold-coated magnetic nanoparticles enables microRNA detection in blood. Nat. Nanotechnol. 13:1066. doi: 10.1038/s41565-018-0232-x

Tegenfeldt, J. O., Prinz, C., Cao, H., Huang, R. L., Austin, R. H., Chou, S. Y., et al. (2004). Micro- and nanofluidics for DNA analysis. Anal. Bioanal. Chem. 378, 1678-1692. doi: 10.1007/s00216-004-2526-0

Tian, K., He, Z., Wang, Y., Chen, S.-J., and Gu, L.-Q. (2013). Designing a polycationic probe for simultaneous enrichment and detection of MicroRNAs in a nanopore. ACS Nano 7, 3962-3969. doi: 10.1021/nn305789z

Tsongalis, G. J., Calin, G., Cordelier, P., Croce, C., Monzon, F., and SzafranskaSchwarzbach, A. E. (2013). MicroRNA analysis: is it ready for prime time? Clin. Chem. 59, 343-347. doi: 10.1373/clinchem.2012.185009

Turchinovich, A., Weiz, L., Langheinz, A., and Burwinkel, B. (2011). Characterization of extracellular circulating microRNA. Nucleic Acids Res. 39, 7223-7233. doi: 10.1093/nar/gkr254

Wang, M., Yu, F., Ding, H., Wang, Y., Li, P., and Wang, K. (2019). Emerging function and clinical values of exosomal MicroRNAs in cancer. Mol. Ther. Nucleic Acids 16, 791-804. doi: 10.1016/j.omtn.2019.04.027

Whitesides, G. M. (2006). The origins and the future of microfluidics. Nature 442:368. doi: 10.1038/nature05058

Wyman, S. K., Knouf, E. C., Parkin, R. K., Fritz, B. R., Lin, D. W., Dennis, L. M., et al. (2011). Post-transcriptional generation of miRNA variants by multiple nucleotidyl transferases contributes to miRNA transcriptome complexity. Genome Res. 21, 1450-1461. doi: 10.1101/gr.118059.110

Yin, H., Zhou, Y., Zhang, H., Meng, X., and Ai, S. (2012). Electrochemical determination of microRNA-21 based on graphene, LNA integrated molecular beacon, AuNPs and biotin multifunctional bio bar codes and enzymatic assay system. Biosens. Bioelectron. 33, 247-253. doi: 10.1016/j.bios.2012.01.014

Zhang, G.-J., Chua, J. H., Chee, R.-E., Agarwal, A., and Wong, S. M. (2009). Labelfree direct detection of MiRNAs with silicon nanowire biosensors. Biosens. Bioelectron. 24, 2504-2508. doi: 10.1016/j.bios.2008.12.035

Zheng, W., Yao, L., Teng, J., Yan, C., Qin, P., Liu, G., et al. (2018). Lateral flow test for visual detection of multiple MicroRNAs. Sens. Actuators B Chem. 264, 320-326. doi: 10.1016/j.snb.2018.02.159

Zhu, D., Zhang, L., Ma, W., Lu, S., and Xing, X. (2015). Detection of microRNA in clinical tumor samples by isothermal enzyme-free amplification and labelfree graphene oxide-based SYBR Green I fluorescence platform. Biosens. Bioelectron. 65, 152-158. doi: 10.1016/j.bios.2014.10.019

Conflict of Interest: The authors declare that the research was conducted in the absence of any commercial or financial relationships that could be construed as a potential conflict of interest.

Copyright (c) 2019 Cacheux, Bancaud, Leichlé and Cordelier. This is an open-access article distributed under the terms of the Creative Commons Attribution License (CC $B Y)$. The use, distribution or reproduction in other forums is permitted, provided the original author(s) and the copyright owner(s) are credited and that the original publication in this journal is cited, in accordance with accepted academic practice. No use, distribution or reproduction is permitted which does not comply with these terms. 